\title{
Sensitivity of Emissions to Uncertainties in Residual Gas Fraction Measurements in Automotive Engines: A Numerical Study
}

\author{
S. M. Aithal $(D)$ \\ Argonne National Laboratory, Lemont, IL 60439, USA \\ Correspondence should be addressed to S. M. Aithal; aithal@mcs.anl.gov
}

Received 21 January 2018; Revised 19 March 2018; Accepted 1 April 2018; Published 2 May 2018

Academic Editor: Constantine D. Rakopoulos

Copyright (c) 2018 S. M. Aithal. This is an open access article distributed under the Creative Commons Attribution License, which permits unrestricted use, distribution, and reproduction in any medium, provided the original work is properly cited.

Initial conditions of the working fluid (air-fuel mixture) within an engine cylinder, namely, mixture composition and temperature, greatly affect the combustion characteristics and emissions of an engine. In particular, the percentage of residual gas fraction (RGF) in the engine cylinder can significantly alter the temperature and composition of the working fluid as compared with the air-fuel mixture inducted into the engine, thus affecting engine-out emissions. Accurate measurement of the RGF is cumbersome and expensive, thus making it hard to accurately characterize the initial mixture composition and temperature in any given engine cycle. This uncertainty can lead to challenges in accurately interpreting experimental emissions data and in implementing real-time control strategies. Quantifying the effects of the RGF can have important implications for the diagnostics and control of internal combustion engines. This paper reports on the use of a well-validated, two-zone quasi-dimensional model to compute the engineout NO and CO emission in a gasoline engine. The effect of varying the RGF on the emissions under lean, near-stoichiometric, and rich engine conditions was investigated. Numerical results show that small uncertainties $(\sim 2-4 \%)$ in the measured/computed values of the RGF can significantly affect the engine-out NO/CO emissions.

\section{Introduction}

The initial temperature, cylinder pressure, and composition of the working fluid (air-fuel mixture) play an important role in determining the combustion characteristics and consequently the emissions from an engine. Characteristics such as ignition delay, flame speed, and combustion stability are affected to varying degrees by the initial conditions of the mixture, depending on the engine operating conditions (e.g., engine speed, load, and ignition timing). These combustion characteristics have a direct impact on the engineout emissions. Factors such as ambient temperature, air humidity, and residual gas introduce a degree of uncertainty in determining the exact initial conditions of the air-fuel mixture in the cylinder at the start of the compression stroke of an engine. The hot burned gas trapped in the clearance volume at the end of the exhaust stroke of the previous engine cycle is referred to as the residual gas [1]. While inlet air temperature and intake air humidity can be measured (albeit at a cost), there is no sensor to measure the amount of residual gas fraction (RGF). The RGF can only be inferred through simulations or an estimation [2]. The difficulties in ascertaining the exact values of the initial conditions of the fuel-air mixture can lead to inaccuracy in model prediction and also analyses and interpretation of experimental data [35]. For instance, the authors of [6] report a very controlled experimental study on the effects of intake air humidity on the performance and emissions of a turbo-charged 4cylinder diesel engine at various engine speeds and loads. The authors of this study reported a $14 \%$ reduction in $\mathrm{NO}_{x}$ with a small addition of moisture $\left(\sim 8 \mathrm{~g}_{\mathrm{H} 2 \mathrm{O}} / \mathrm{kg}_{\text {air }}\right.$ or $1.35 \%$ ) thus highlighting the importance of the initial mixture composition on engine-out $\mathrm{NO}$ emissions. The residual gas consists of $\mathrm{CO}_{2}, \mathrm{H}_{2} \mathrm{O}$, nitrogen, and excess $\mathrm{O}_{2}$, along with other minor combustion products such as NO, CO, and $\mathrm{OH}$, and is typically above $350^{\circ} \mathrm{C}$ (depending on the engine operating conditions). The amount of residual gas depends on the compression ratio, valve location, and valve overlap. 
The residual gas (from the previous cycle) mixes with the fresh incoming charge of air and fuel inducted into the engine in the next cycle, thus altering the average temperature and mixture composition. In spark-ignited engines, the values of the RGF are estimated to be between $3 \%$ and $7 \%$ under full-load conditions but can be as high as $20 \%$ under partload conditions. The RGF is smaller in Diesel engines on account of the larger compression ratio [7]. Based on the results shown in [6], it is clear that RGF will impact the initial mixture composition and temperature and consequently the engine-out emissions. RGF acts as an internal EGR (exhaust gas recirculation) and impacts engine-out emissions akin to external EGR via dilution, chemical, and thermal effects. Gasoline engines are usually operated close to stoichiometric; hence little oxygen is present in the residual gas, whereas in diesel engines (which typically run lean) considerable amounts of $\mathrm{O}_{2}$ can be present. The concentration of $\mathrm{O}_{2}$ in the engine cylinder has a strong impact on the flame propagation and kinetics (chemical effect). Furthermore, $\mathrm{CO}_{2}$ and $\mathrm{H}_{2} \mathrm{O}$ (major components of the RGF) have higher specific heats than do $\mathrm{N}_{2}$ and $\mathrm{O}_{2}$ (main components of incoming air). As a result, the mixture-averaged ratio of specific heats $(\gamma)$ of the working fluid is lowered, thus altering the temporal variation of cylinder pressure and temperature (thermal effect) [8]. The presence of $\mathrm{CO}_{2}$ and $\mathrm{H}_{2} \mathrm{O}$ in the initial engine charge can also affect the combustion kinetics and hence the ignition delay. Given these considerations, understanding the role of residual gas is important from an emissions standpoint. Several investigations, both experimental and numerical, have been conducted to determine the RGF [9-18]. Uncertainties in measurements, however, can lead to errors in the estimates of RGF. For instance, [19] points out that a 5\% error incylinder pressure measurement can lead to a $2-3 \%$ error in the estimation of the RGF. Understanding the sensitivity of the engine-out emissions to the percentage of RGF in the engine cylinder is important from the standpoint of model calibration and engine data interpretation. Moreover, the sensitivity of emissions to the uncertainty in the RGF is also important for designing robust real-time controls to minimize emissions while maximizing performance and fuel economy. There is currently no experimental data or numerical investigation evaluating the sensitivity of engineout $\mathrm{NO}$ and $\mathrm{CO}$ on the RGF and hence the focus of this numerical study.

Reported here is a systematic investigation of the sensitivity of engine-out NO and CO emission to small uncertainties in the measured/estimated values of RGF. In the absence of experimental data, numerical investigations can provide useful insight into effects of RGF on engine-out emissions. Conducting detailed multidimensional engine simulations with detailed chemistry require large computation resources. A typical parallel computation conducted on a single-cylinder engine over one cycle requires about 24-48 hours on about $30-50$ cores. The prohibitively large computational resources required for multidimensional simulations preclude their use in conducting large parametric studies required for design/optimization. Reduced order models are ideally suited for conducting parametric studies in such cases. In this numerical study, a well-validated, fast, robust, two-zone quasi-dimensional model was used. A single-cylinder gasoline engine operating under lean $(\phi \sim$ $0.8)$, near-stoichiometric $(\phi \sim 1.0)$, and rich $(\phi \sim 1.12)$ conditions was investigated. Most gasoline engines run close to stoichiometric; however, the lean and rich cases also were studied in order to understand the impact of the RGF for extreme cases of $\mathrm{O}_{2}$ concentration in the working fluid. The fuel mass, initial cylinder pressure, and RPM were fixed for each of these air-fuel mixtures (lean to rich conditions). The RGF was varied from $0 \%$ (no RGF) to $7 \%$ in each case, and the temporal variation of $\mathrm{NO}$ and $\mathrm{CO}$ for each of these cases was computed by using reduced-order rate models. A small range of RGF variation was used in this study to assess the sensitivity of $\mathrm{NO}$ and $\mathrm{CO}$ emissions to small inaccuracies in experimental measurements/numerical estimates. Fast and robust quasi-dimensional models can be used not only for detailed analyses of a single engine cycle but also for analysis of complete engine drive cycles [20]. The ability to conduct sensitivity analyses on complete drive cycles in real-time is necessary because stringent emissions standards in the future will necessitate a cycle-by-cycle analysis of drive cycles. This work lays the foundation for both single-cycle and drive-cycle analyses to understand the impact of RGF on emissions and thus has potential for use in engine data interpretation and model calibration over a wide engine operating range.

This paper is organized as follows. Sections 2 and 3 briefly describe the model and the method of solution, respectively. Section 4 describes model validation while Section 5 discusses results for the single-cylinder gasoline engine. Section 6 briefly summarizes the main findings of this work.

\section{Mathematical Formulation}

This section describes the two-zone quasi-dimensional model used to compute the temporal variation of the average cylinder pressure along with the burned and unburned gas temperature in a spark-ignited engine. The modified reaction rate-controlled models for $\mathrm{NO}$ and $\mathrm{CO}$ are also described in this section.

2.1. Two-Zone Model for Computing Temporal Variations of Temperature and Pressure. A numerical model used to compute the temporal variation of temperature and pressure in a single-cylinder diesel engine was described in detail in [8]. A similar methodology was used in this work to model a spark-ignited engine. Temporal variation of the engine pressure and temperature during the compression and power stroke was obtained by a numerical solution of the energy equation as in [8].

The energy equation describing the variation of pressure with crank angle is as follows.

$$
\frac{d P(\theta)}{d \theta}=\frac{\gamma-1}{V(\theta)}\left(Q_{\text {in }}-Q_{\text {loss }}\right)-\gamma \frac{P(\theta)}{V(\theta)} \frac{d V}{d \theta} .
$$

The amount of heat produced $\left(Q_{\text {in }}\right)$ due to the fuel burned $\left(m_{\mathrm{fb}}(d \theta)\right)$ from $\theta$ and $\theta+d \theta$ is given by

$$
Q_{\text {in }}=\left(H_{p}(T)-H_{R}(T)\right) \cong m_{\mathrm{fb}}(d \theta) \mathrm{LHV}
$$


while the heat lost from the engine during the interval is given by

$$
Q_{\text {loss }}=\frac{h_{c g} A}{\omega}\left(T(\theta)-T_{w}\right) .
$$

The wall temperature $\left(T_{w}\right)$ in (3) was assumed to be constant at $400^{\circ} \mathrm{K}$ in this work.

The instantaneous values of volume $(V(\theta))$ and area $(A)$ are given by the slider-crank model as discussed in $[7,8]$

The convective heat transfer coefficient is expressed by the well-known Woschni correlation and is expressed as [21]

$$
h_{c g}=3.26 D^{-0.2} P^{0.8} T^{-0.55} w^{0.8},
$$

where 3.26 is the scaling factor in the Woschni correlation.

The velocity of the burned gas $w$ in (4) is given by

$$
w=c_{1} S_{p}+c_{2} \frac{V_{d} T_{r}}{p_{r} V_{r}}\left(P(\theta)-P_{m}\right) .
$$

Effects of temperature and mixture composition on the thermophysical properties of the working fluid were included in the solution of the energy equation. Temporal variations of the thermophysical properties of all the species in the gas mixture were obtained by using thermodynamic coefficients from the CHEMKIN database. Computing the temporal variation of the thermophysical properties of the working fluid correctly as a function of mixture composition and temperature is extremely important in order to predict the engine pressure and temperature correctly as pointed out in [8]. Many quasi-dimensional models use constant values for the ratio of specific heats $(\gamma)$ during the compression and expansion strokes, which can lead to inaccuracies in computed engine pressure and consequently in the temperature and emissions. This situation is especially true for lean mixtures or engines running on high EGR fractions. Temperature dependent polynomial expressions for specific heat $\left(C_{p, k}\right)$, enthalpy $\left(H_{k}\right)$, and internal energy $\left(U_{k}\right)$ of individual species in the working fluid were computed using the procedure discussed in [22].

Mixture-averaged values of specific heat of the working fluid were averaged by using mole fractions as follows.

$$
\begin{gathered}
\overline{C_{v}}=\sum_{k=1}^{K} X_{k} C_{v, k} ; \\
\overline{C_{p}}=\sum_{k=1}^{K} X_{k} C_{p, k}, \\
\gamma=\frac{\overline{C_{p}}}{\overline{C_{v}}} .
\end{gathered}
$$

Following the procedure in [8], fuel combustion chemistry was modeled by a single-step global reaction. The combustion process of the premixed fuel-air mixture after the spark was modeled by using the well-known Wiebe function [7].

$$
x_{b}(\theta)=\frac{m_{\mathrm{fb}}}{m_{\mathrm{fT}}}=\left\{1-\exp \left\{-a\left(\frac{\theta-\theta_{0}}{\theta_{b}}\right)^{m+1}\right\}\right\},
$$

where $\theta, \theta_{0}$, and $\theta_{b}$ are the instantaneous crank angle, the crank angle for the start of combustion, and the combustion duration, respectively. Further, $m_{\mathrm{fb}}$ is the fuel burned, $m_{\mathrm{fT}}$ is the total fuel at BDC, and $x_{b}(\theta)-x_{b}(\theta-1)$ is the fraction of fuel mass burned in each crank angle and is used to compute $Q_{\text {in }}$ in (2). The Wiebe function constants; namely, " $a$," " $m$," and " $\theta_{b}$ " are functions of various parameters such as engine geometry, fuel type, air-fuel ratio, engine speed, and load.

The average gas temperature was obtained as follows:

$$
T(\theta)=\frac{P(\theta) V(\theta)}{m(\theta) R_{u}} .
$$

The Wiebe function can be used to compute the mass of fuel burned at each crank angle. The species in the burned and unburned zones are computed so as to ensure a total elemental balance (and hence mass balance) in the cylinder. Knowing the masses of the burned and unburned zones, the burned and unburned gas temperature were obtained as

$$
\begin{aligned}
& T_{b}(\theta)=\frac{P(\theta) V(\theta)}{m_{b}(\theta) R_{g b}}, \\
& T_{u}(\theta)=\frac{P(\theta) V(\theta)}{m_{u}(\theta) R_{g u}},
\end{aligned}
$$

where the subscripts " $u$ " and " $b$ " represent unburned and burned quantities, respectively. It was assumed that there is no heat transfer between the burned and unburned zone, for the sake of simplicity. The volume fraction of the burned gas $y_{b}\left(=V_{b} / V\right)$ can be obtained by using the following relationship [7].

$$
x_{b}(\theta)=\left[1+\frac{\rho_{u}}{\rho_{b}}\left\{\frac{1}{y_{b}}-1\right\}\right]^{-1} .
$$

Following [7], $\rho_{u} / \rho_{b}=4$ was used for the sake of simplicity.

The moles of $\mathrm{CO}_{2}, \mathrm{H}_{2} \mathrm{O}, \mathrm{O}_{2}$, and $\mathrm{N}_{2}$ produced in CAD $d \theta$ in accordance with the single-step global chemistry model are as follows.

$$
\begin{aligned}
& n_{\mathrm{co} 2}(d \theta)=x_{1}\left\{\frac{\left(x_{b}(\theta)-x_{b}(\theta-d \theta)\right)}{M_{f}}\right\}, \\
& n_{\mathrm{H} 2 \mathrm{O}}(d \theta)=\frac{y_{1}}{2}\left\{\frac{\left(x_{b}(\theta)-x_{b}(\theta-d \theta)\right)}{M_{f}}\right\}, \\
& n_{\mathrm{O} 2}(d \theta) \\
& =\left(\frac{1}{\varphi}-1\right)\left(x_{1}+\frac{y_{1}}{4}\right)\left\{\frac{\left(x_{b}(\theta)-x_{b}(\theta-d \theta)\right)}{M_{f}}\right\},
\end{aligned}
$$

$n_{\mathrm{N} 2}(d \theta)$

$$
=\left(\frac{\beta}{\varphi}\right)\left(x_{1}+\frac{y_{1}}{4}\right)\left\{\frac{\left(x_{b}(\theta)-x_{b}(\theta-d \theta)\right)}{M_{f}}\right\},
$$

where $x_{1}$ is the number of carbon atoms, $y_{1}$ is the number of hydrogen atoms, and $M_{f}$ is the molecular weight of the fuel. 
In (13) and (14), $\phi$ and $\beta$ denote the equivalence ratio and ratio of $\mathrm{N}_{2}: \mathrm{O}_{2}$ moles in air (typically 3.76).

The total number of moles of any species $\left(\mathrm{CO}_{2}, \mathrm{H}_{2} \mathrm{O}, \mathrm{O}_{2}\right.$, and $\mathrm{N}_{2}$ ) in the burned zone at any crank angle $\theta$ is

$$
n_{N}=\sum_{\theta=\theta_{i}}^{\theta} n_{N}(d \theta)
$$

where the summation is over the crank angle interval from $\theta_{i}$ (SOI) to $\theta$. Since the initial moles of fuel, $\mathrm{O}_{2}$, and $\mathrm{N}_{2}$, are known, the composition of the burned zone (and hence unburned zone) can be computed based on (11)-(15).

2.2. Modified Rate-Controlled NO Model. The extended Zeldovich mechanism was used to derive a rate expression for the time rate of change of NO concentration. Details of the mechanism and rates can be found in [7] (page 573). Based on the extended Zeldovich mechanism, the expression for the time rate of change of $\mathrm{NO}$ is as follows.

$$
\begin{aligned}
\frac{d[\mathrm{NO}]}{d t}= & k_{1}^{+}[\mathrm{O}]\left[\mathrm{N}_{2}\right]+k_{2}^{+}[\mathrm{N}]\left[\mathrm{O}_{2}\right]+k_{3}^{+}[\mathrm{N}][\mathrm{OH}] \\
& -k_{1}^{-}[\mathrm{NO}][\mathrm{N}]-k_{2}^{-}[\mathrm{NO}][\mathrm{O}] \\
& -k_{3}^{-}[\mathrm{NO}][\mathrm{H}]
\end{aligned}
$$

Following the simplifying assumptions in [7],

$$
\frac{d[\mathrm{NO}]}{d t}=2 k_{1}^{+}[\mathrm{O}]\left[\mathrm{N}_{2}\right]-2 k_{1}^{-}[\mathrm{NO}][\mathrm{N}] \text {. }
$$

Equilibrium concentrations of $\mathrm{O}, \mathrm{N}_{2}, \mathrm{NO}, \mathrm{H}, \mathrm{OH}$, and $\mathrm{O}_{2}$ are used in computing the RHS of (17). Equation (17) holds true under constant volume conditions. In an IC engine, the volume of the cylinder varies with time.

Since the concentration $[\mathrm{NO}]=N_{\mathrm{NO}} / V(t)$, where $N_{\mathrm{NO}}$ is the number of moles of $\mathrm{NO}$ and $V(t)$ is the instantaneous volume of the cylinder, the LHS of (17) can be rewritten as discussed in [23]

$$
\begin{aligned}
\frac{d[\mathrm{NO}]}{d t} & =\frac{d}{d t}\left(\frac{N_{\mathrm{NO}}}{V(t)}\right) \\
& =\frac{1}{V(t)} \frac{d N_{\mathrm{NO}}}{d t}+\frac{d}{d t}\left\{\frac{1}{V(t)}\right\} N_{\mathrm{NO}}
\end{aligned}
$$

which can be shown to yield

$$
\frac{d[\mathrm{NO}]}{d t}=\left.\frac{d[\mathrm{NO}]}{d t}\right|_{\mathrm{H}}-[\mathrm{NO}] \frac{1}{V_{b}} \frac{d V_{b}}{d t},
$$

where $\left.(d[\mathrm{NO}] / d t)\right|_{\mathrm{H}}$ is the rate of change of NO concentration at constant volume computed using (17). The second term on the RHS of (18) accounts for the decrease in NO concentration as a result of the increasing cylinder volume during the expansion stroke.

From SOI to EOC, the burned volume $V_{b}$ can be computed based on the procedure discussed earlier. After EOC, $V_{b}=V(\theta)$, where $V(\theta)$ is the cylinder volume at crank angle $\theta$. Equation (19) is referred to as the modified reaction ratecontrolled NO model in this work because it accounts for the rate of change of the engine volume in determining the NO concentration during the engine cycle.

The rate constants and equilibrium concentrations of species used in evaluating (19) are computed by using the burned gas temperature and pressure at a given crank angle. Effects of mixing between the burned and unburned gas and the temperature gradients in the burned gas region are neglected. Solution of (19) yields the temporal variation of NO concentration (in moles $/ \mathrm{cm}^{3}$ ).

2.3. Modified Rate-Controlled CO Model. The modified ratecontrolled CO model used in this work is an adaptation of the model discussed in [24]. Similar to (19), the modified CO model used in this work can be written as

$$
\frac{d[\mathrm{CO}]}{d t}=\left.\frac{d[\mathrm{CO}]}{d t}\right|_{\mathrm{cv}}-[\mathrm{CO}] \frac{1}{V_{b}} \frac{d V_{b}}{d t} .
$$

$\left.(d[\mathrm{CO}] / d t)\right|_{\mathrm{cv}}$ in (20) is the rate of change in concentration of $\mathrm{CO}$ at constant volume and is expressed as

$$
\left.\frac{d[\mathrm{CO}]}{d t}\right|_{\mathrm{cv}}=\left(C_{\mathrm{co}} R_{1}+R_{2}+R_{3}\right)\left\{1-\frac{|\mathrm{CO}|}{|\mathrm{CO}|_{\mathrm{eq}}}\right\},
$$

where $C_{\mathrm{co}}$ is the calibration parameter. $C_{\mathrm{co}}$ can be evaluated using the ratio between experimental data and model predictions obtained by setting $C_{\mathrm{co}}=1$ for a given set of operating conditions. This calibrated value of $C_{\text {co }}$ is kept the same for all other operating conditions.

Details of (21) along with reaction rates are described in [24] (see Eq. 28). The concentration of all terms required to evaluate the RHS of (21) is equilibrium values at a given temperature and pressure corresponding to a given crank angle.

\section{Computational Details}

The two-zone quasi-dimensional model described above was used to study the performance and emissions of a singlecylinder gasoline engine. Iso-Octane $\left(\mathrm{C}_{8} \mathrm{H}_{18}\right)$ was used as a surrogate for gasoline for the sake of simplicity. In (11) through (14), $x_{1}=8$ and $y_{1}=18 ; \beta$, the $\mathrm{N}_{2}: \mathrm{O}_{2}$ ratio in air, is taken to be 3.76 and $M_{f}$ is the molecular mass of the fuel (114 gm/mole for Iso-Octane). Three different equivalence ratios $(\phi)$, namely, $\phi=0.8$ (lean), 1.0 (stoichiometric), and 1.12 (rich), were considered. The engine torque for each of these cases was kept constant at $17 \mathrm{Nm}$. The fuel mass and initial cylinder pressure at bottom dead center (BDC) were kept constant for each of these cases considered. The RGF was varied from $0 \%$ to $7 \%$ for all the equivalence ratios considered in this work. Since the RGF fraction considered in this work is small, it has an insignificant impact on the combustion characteristics (burn rate) and hence the same Wiebe parameters were used for all cases considered in this work for simplicity. The RGF was assumed to consist of $\mathrm{CO}_{2}$, $\mathrm{H}_{2} \mathrm{O}, \mathrm{N}_{2}$, and excess $\mathrm{O}_{2}$ (for lean cases). The initial cylinder temperature at BDC was computed as a mass-averaged temperature of the incoming air and assumed percentage RGF. 
The initial cylinder gas composition (moles of $\mathrm{O}_{2}, \mathrm{~N}_{2}, \mathrm{H}_{2} \mathrm{O}$, $\mathrm{CO}_{2}$, and fuel) was computed on the basis of the pressure (at $\mathrm{BDC})$, mass-averaged temperature, equivalence ratio, and the RGF.

The numerical procedure to obtain the cylinder pressure in a diesel engine is explained in detail in [8]. The same procedure was adapted to obtain the pressure and temperature in an SI engine using the equations described above. Briefly, for a given set of operating conditions, namely, the prescribed mass of the fuel-air-RGF mixture and temperature at BDC, (1) was solved iteratively by using (2)-(10) to obtain the cylinder pressure from $\theta=-180$ (BDC) to $\theta=\theta_{\mathrm{EVO}}$ (crank angle for exhaust valve opening) in increments of $0.5^{\circ} . \theta_{\mathrm{EVO}}$ was set at $140^{\circ}$ in each of the cases considered. For a given pressure at a crank angle, the burned and unburned gas temperatures were obtained by using (9).

The engine dimensions and operating conditions used in this work are shown in Tables 1 and 2, respectively.

The burned zone comprised $\mathrm{CO}_{2}, \mathrm{H}_{2} \mathrm{O}$, excess $\mathrm{O}_{2}$, and the corresponding amount of $\mathrm{N}_{2}$, whereas the unburned zone comprised the unburned fraction of fuel, $\mathrm{O}_{2}$, and $\mathrm{N}_{2}$. Equations (11)-(15) explain the procedure to compute the composition of the burned zone.

Knowing the temporal variation of temperature, pressure, and elemental composition of the burned zone (from (11) to (15)), one can compute the temporal variation of NO and CO using (19) and (20), respectively. As explained earlier, the solution of these equations requires computing equilibrium concentrations of $\mathrm{O}, \mathrm{N}, \mathrm{OH}, \mathrm{H}, \mathrm{O}_{2}, \mathrm{CO}, \mathrm{CO}_{2}$, and $\mathrm{N}_{2}$ at every crank angle. Computation of equilibrium concentrations is very time-consuming. For this purpose, a fast, accurate, and robust solver based on the equilibrium constant method described in detail in [25] was used. The equilibrium solver discussed in [25] enables the computation of the equilibrium concentrations required for computing (19) and (20) extremely fast (on the order of a few microseconds for a given temperature, pressure, and mixture composition). The coupling of the energy equation with the fast, equilibrium solver (needed to compute the equilibrium concentrations) is extremely important to enable the computing of performance and emissions in an entire engine cycle in milliseconds.

\section{Model Validation}

The two-zone model described in Section 2 was validated by detailed comparison of cylinder pressure and engine-out $\mathrm{NO}$ and $\mathrm{CO}$ predictions with experimental data reported in [26]. Figures 1-3 show detailed validation of pressure, $\mathrm{NO}$, and CO obtained using the two-zone model used in this work. Figure 1 shows that the model matches the engine pressure well. The discrepancy between experimental data and the model for $-10^{\circ} \leq \theta \leq 2^{\circ}$ can be attributed to the heat loss from the engine. References $[27,28]$ investigated the effect of different well-known heat transfer correlations on engine pressure and reported significant differences between the predicted pressures, especially during the compression stroke. Furthermore, the quasi-dimensional model used in this work does not have a crevice model which could also
TABLE 1: Engine dimensions (in $\mathrm{mm}$ ).

\begin{tabular}{lc}
\hline Bore & 59 \\
Stroke & 103 \\
Compression ratio & 8.1 \\
Length of connecting rod & 255 \\
\hline
\end{tabular}

TABLE 2: Operating conditions used in this work.

\begin{tabular}{lc}
\hline Speed $(\mathrm{rpm})$ & 1100 \\
Inlet air temperature & $30^{\circ} \mathrm{C}$ \\
RGF temperature & $350^{\circ} \mathrm{C}$ \\
Spark timing & $26 \mathrm{btDC}$ \\
\hline
\end{tabular}

lead to the pressure discrepancy between the model and experimental data. Overall, the pressure profile predicted by the model compares well with experimental data. The magnitude and location of the peak pressure, which is important from the standpoint of predicting emissions is captured well by the model. Figure 2 shows a comparison of the engine-out NO predicted by the model and experimental data. It is seen that the model correctly captures the wellknown trend of $\mathrm{NO}$ variation with equivalence ratio [7]. The $\mathrm{NO}$ formation depends on the concentrations of $\mathrm{N}_{2}$ and $\mathrm{O}_{2}$ and also the temperature of the burned gas mixture. While the temperature of the burned gas mixture is higher under nearstoichiometric conditions (as compared to lean mixtures), the concentrations of $\mathrm{N}_{2}$ and $\mathrm{O}_{2}$ of lean mixtures are higher than that of near-stoichiometric mixtures. Given the opposing effects of temperature and species concentration of $\mathrm{N}_{2}$ and $\mathrm{O}_{2}$ on the NO formation rate, the maximum NO formation occurs for $0.8<\varphi<0.85$. Figure 2 shows that the predicted $\mathrm{NO}$ is about $7 \%$ higher than experimentally observed engineout NO. This difference can be attributed to the fact that the two-zone model used in this work does not include the effects of mixing and heat loss to the surrounding unburned gas. In the actual engine, the burned gas temperature is lower due to effects of heat exchange between the burned gas and the unburned gas, thus lowering the temperature of the burned gas region. Despite the simplifying assumptions in the twozone model, the model predicts engine-out NO well. Figure 3 shows a comparison between experimentally measured engine-out $\mathrm{CO}$ and the model predictions. It is observed that the model captures $\mathrm{CO}$ formation characteristics well.

\section{Results and Discussions}

Experiments investigating the impact of the sensitivity of RGF on engine-out emissions are unavailable. Hence this section discusses the impact of variations in the RGF on engine-out $\mathrm{NO}$ and $\mathrm{CO}$ based on the numerical results obtained using the well-validated quasi-dimensional model described in Section 2 for conditions described in Section 3.

As discussed earlier, the cylinder pressure at BDC was kept constant for a given equivalence ratio, for all RGF fractions considered. Since the cylinder pressure at BDC can be computed using the ideal gas law

$$
P_{\mathrm{BDC}}=\rho R_{g} T_{\text {avg }},
$$




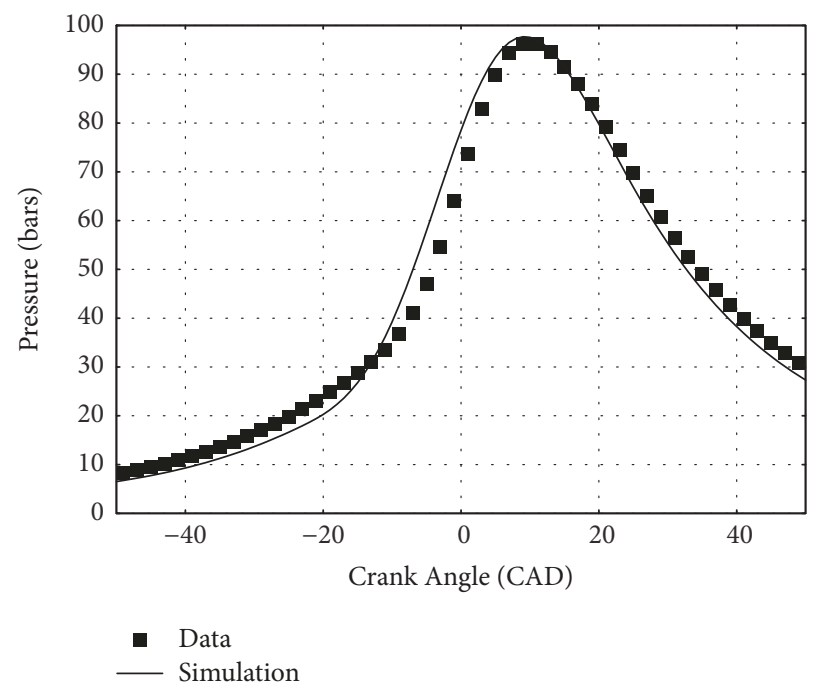

FIGURE 1: Temporal cylinder pressure (simulation and experimental data).

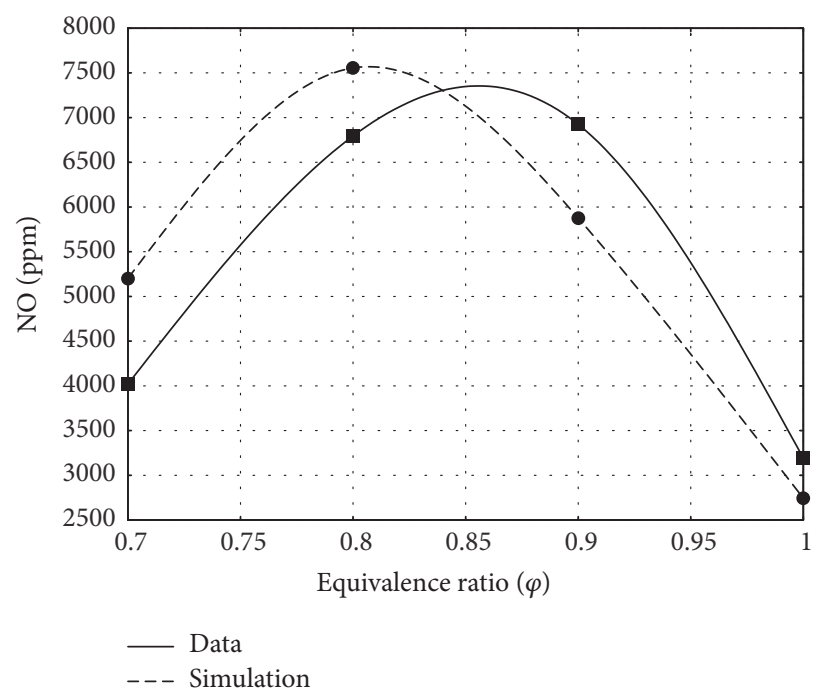

FIGURE 2: Comparison of predicted engine-out NO with experimental data for various equivalence ratios.

where the average density is computed as

$$
\rho=\frac{m_{\mathrm{air}}+m_{\mathrm{rgf}}}{V_{\mathrm{BDC}}}
$$

and $T_{\text {avg }}$ is the mass-weighted average of the incoming air $\left(T_{\text {air }}\right)$ at $30^{\circ} \mathrm{C}$ and the residual gas $\left(T_{\text {rgf }}\right)$ is assumed to be at $350^{\circ} \mathrm{C}$

$$
T_{\mathrm{avg}}=\frac{T_{\mathrm{air}} m_{\mathrm{air}}+T_{\mathrm{rgf}} m_{\mathrm{rgf}}}{m_{\mathrm{air}}+m_{\mathrm{rgf}}} .
$$

An increase in the percentage of RGF at BDC, implies an increase both in the mass of the residual gas $\left(m_{\text {rgf }}\right)$ and the average temperature $\left(T_{\mathrm{avg}}\right)$ and hence a decrease in the mass of air. A reduction in the mass of incoming air implies a decrease in the moles of $\mathrm{N}_{2}$ and $\mathrm{O}_{2}$ in the working fluid.
Figure 4 shows the variation of inlet air mass for each of the air-fuel ratios considered in this work. As explained above, an increase in the \% RGF decreases the mass of incoming air for all the equivalence ratios considered in this work.

The complete single step combustion of a hydrocarbon (lean and stoichiometric) can be represented as

$$
\begin{aligned}
\mathrm{C}_{x} \mathrm{H}_{y} & +\frac{1}{\emptyset}\left(\mathrm{O}_{2}+\beta \mathrm{N}_{2}\right) \\
& =x \mathrm{CO}_{2}+\frac{y}{2} \mathrm{H}_{2} \mathrm{O}+\left(1-\frac{1}{\varphi}\right) \mathrm{O}_{2}+\frac{\beta}{\varphi} \mathrm{N}_{2} .
\end{aligned}
$$

For $\mathrm{C}_{8} \mathrm{H}_{18}, x=8$ and $y=18$; hence complete combustion of 1 mole of gasoline would yield 8 moles of $\mathrm{CO}_{2}$ and 9 moles of $\mathrm{H}_{2} \mathrm{O}$.

Figures 5, 6, and 7 show the variation of the moles of $\mathrm{CO}_{2}$, $\mathrm{H}_{2} \mathrm{O}$, and $\mathrm{CO}$ in the burned gas zone normalized by the total 


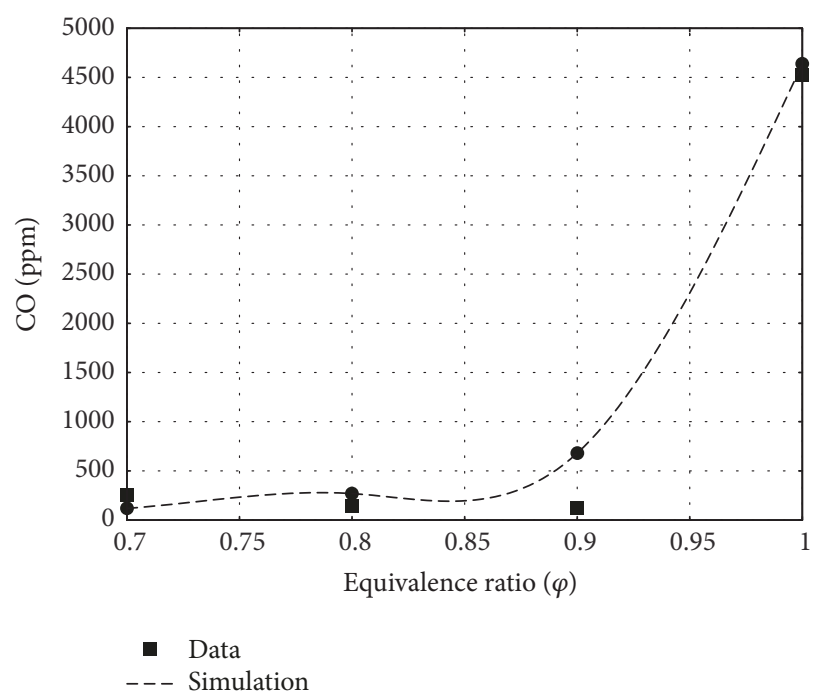

FIGURE 3: Comparison of predicted engine-out $\mathrm{CO}$ with experimental data for various equivalence ratios.

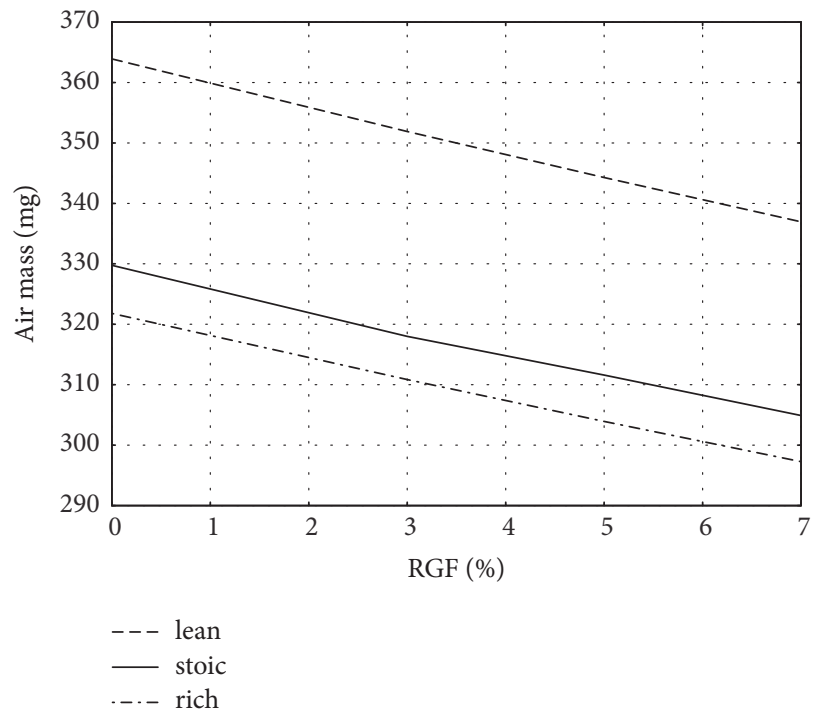

FIGURE 4: Variation of initial cylinder air mass with RGF.

number of fuel moles with no residual gas in the initial mixture $(\% \mathrm{RGF}=0)$. During the expansion stroke, the lean and stoichiometric cases show that the normalized moles of $\mathrm{CO}_{2}$ and $\mathrm{H}_{2} \mathrm{O}$ are near the theoretically expected values and the moles of $\mathrm{CO}$ are insignificant. For rich mixtures, there is insufficient oxygen for complete combustion; hence the moles of $\mathrm{CO}_{2}$ and $\mathrm{H}_{2} \mathrm{O}$ after combustion are below the expected theoretical values. Rich mixtures also show a significantly larger concentration of $\mathrm{CO}$, compared to the lean and stoichiometric cases.

Figure 8 shows the impact of the percentage of RGF on the maximum burned gas temperature for all the equivalence ratios studied in this work. The peak burned gas temperature of the stoichiometric mixture is higher than the peak burned gas temperature of the lean and rich mixtures, for each of the RGF cases. This is a well-known phenomenon in the combustion of hydrocarbon fuels [29]. For lean mixtures, an increase in the RGF leads to a rise in maximum temperature. Since the pressure at BDC is held constant for each of the equivalence ratio considered, a decrease in the mass of the working fluid as shown in Figure 4 leads to a higher peak burned temperature, as required by (14). However, this trend is reversed in stoichiometric and rich mixtures in spite of a drop in the mass of the working fluid. This can be explained on the basis of incomplete combustion. As the percentage of RGF in the mixture increases, the mass of incoming air decreases which leads to a decrease in the $\mathrm{O}_{2}$ content of the fuel-air-RGF mixture. The reduction in the $\mathrm{O}_{2}$ content of the working fluid leads to incomplete fuel combustion. In other words, the lack of sufficient $\mathrm{O}_{2}$ in the mixture means that all fuel moles are not completely converted to the theoretically expected moles of $\mathrm{CO}_{2}$ and $\mathrm{H}_{2} \mathrm{O}$ but produces 


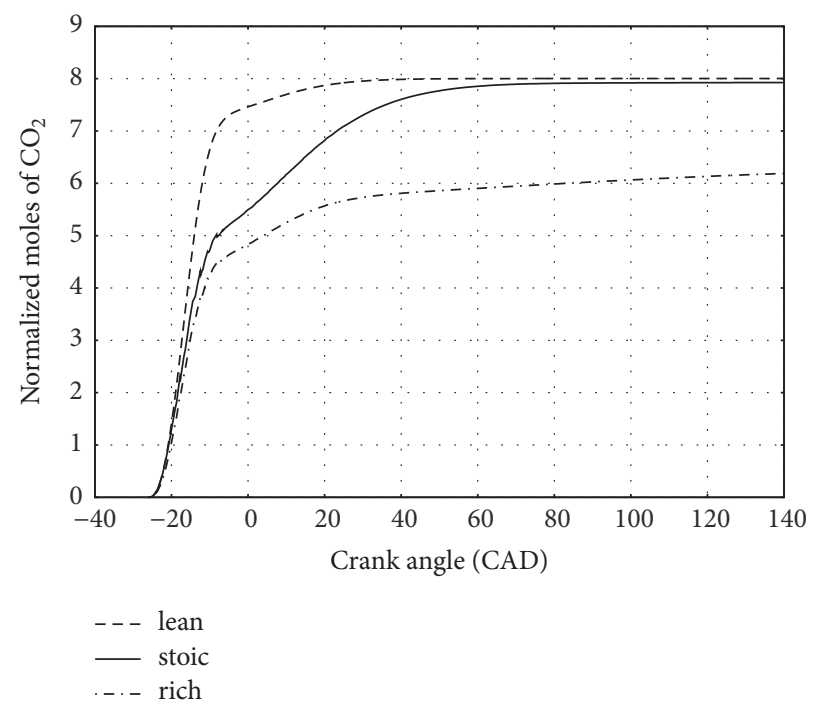

Figure 5: Variation of normalized moles of $\mathrm{CO}_{2}$ with crank angle.

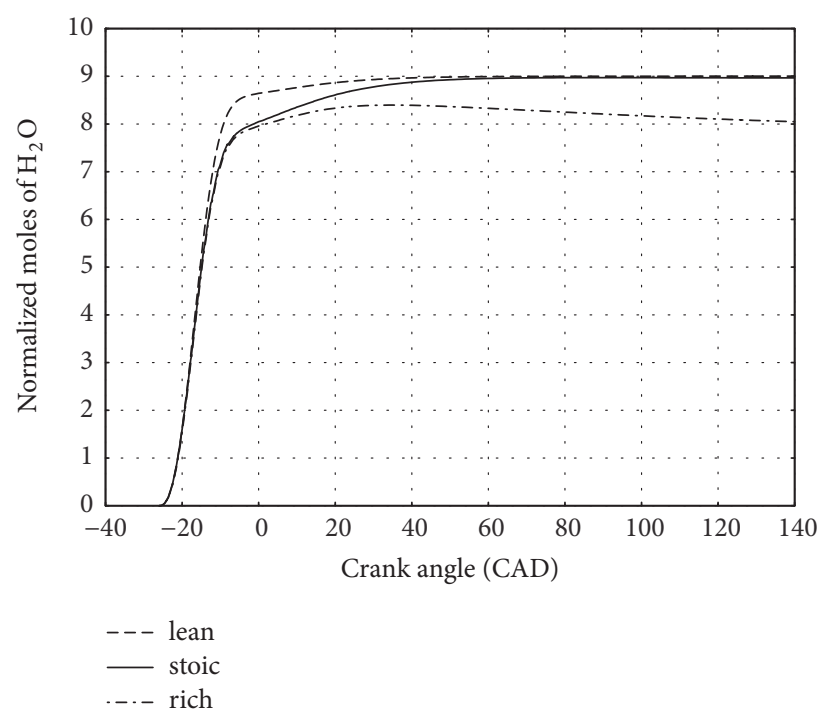

Figure 6: Variation of normalized moles of $\mathrm{H}_{2} \mathrm{O}$ with crank angle.

a larger fraction of $\mathrm{CO}$. $\mathrm{CO}$ is a fuel that can be combusted to generate additional thermal energy via the exothermic reaction [1]

$$
2 \mathrm{CO}+\mathrm{O}_{2}=2 \mathrm{CO}_{2}+\text { heat. }
$$

The reduction in maximum burned gas temperatures in rich mixtures is due to the loss of thermal energy from the conversion of $\mathrm{CO}$ to $\mathrm{CO}_{2}$ as shown in (26). Of note is the fact that the stoichiometric mixture (at RGF $=0 \%$ ) becomes rich when the RGF is introduced.

The percentage drop in the peak temperature is close to the percentage of RGF introduced into the mixture, both for stoichiometric and for rich mixtures. In other words, introducing a 3\% RGF in the working fluid drops the peak temperature (of the $0 \%$ RGF mixture) by about $3 \%$.
Figure 9 shows the impact of the percentage of RGF on engine-out $\mathrm{NO}$ for the three equivalence ratios considered. As expected, for any given RGF, lean mixtures produce a higher engine-out NO than do the stoichiometric and rich mixtures. Furthermore, for a given equivalence ratio, increasing the RGF reduces NO. The reason for this trend is as follows. Increasing the RGF reduces the mass of fresh air (hence $\mathrm{O}_{2}$ ) in the mixture (dilution effect of the RGF). Despite the increased peak temperature (for lean mixtures) the reduced mass of $\mathrm{O}_{2}$ and $\mathrm{N}_{2}$ in the initial working fluid lowers NO. The RGF acts as an internal exhaust gas recirculation (EGR) and hence leads to NO reduction. The percentage of RGF has a significant impact on the engine-out NO for both lean and rich mixtures. For instance, the numerical results show that, for lean mixtures, if the measured/estimated RGF $=5 \%$ with a $\pm 2 \%$ error in the measurement/estimate, the error in the predicted NO is about $20 \%$. The error is even more severe, 


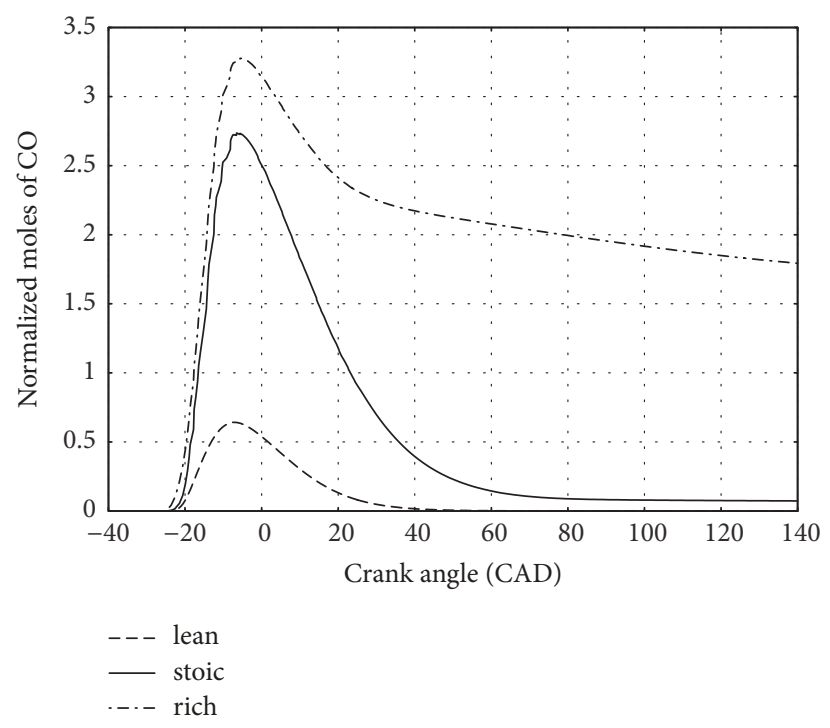

FIGURE 7: Variation of normalized moles of CO with crank angle.

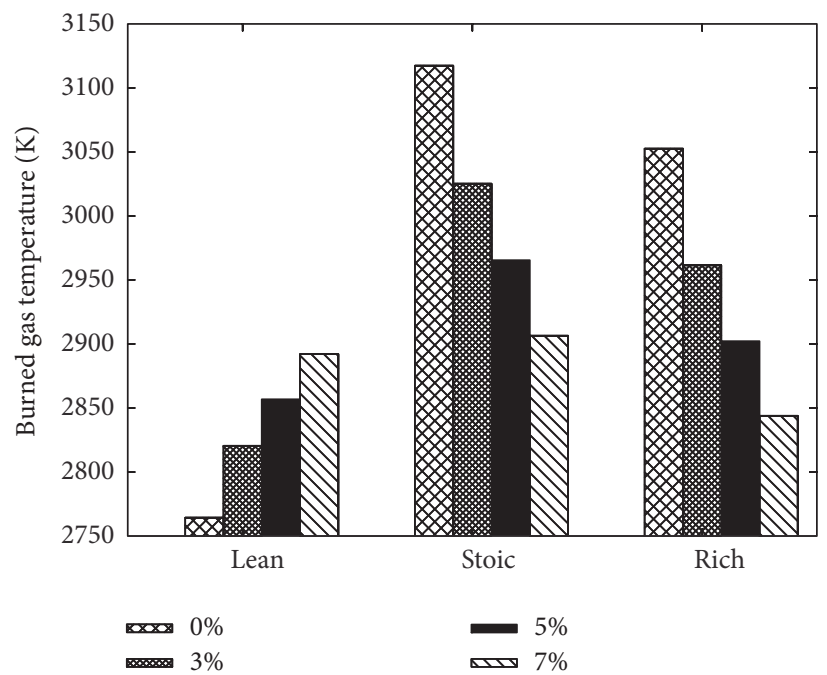

FIGURE 8: Effect of RGF and equivalence ratio on maximum burned gas temperature (K).

if one were to note that, for lean mixtures, at RGF $=7 \%$, there is about a $45 \%$ reduction in $\mathrm{NO}$ as compared with $\mathrm{RGF}=0$. Rich mixtures show about a $70 \%$ reduction in NO at an RGF of $7 \%$ as compared with $\mathrm{RGF}=0$. These results show that even a slight inaccuracy in the computed/measured value of the RGF fraction can have a significant impact on the engine-out NO.

Figure 10 shows the impact of the percentage of RGF on engine-out $\mathrm{CO}$ for the three equivalence ratios considered. As expected, for any given RGF, lean mixtures produce a lower engine-out $\mathrm{CO}$ than do the rich mixtures. Furthermore, as the percentage of RGF increases, the engine-out $\mathrm{CO}$ increases for all the equivalence ratios. As with engine-out $\mathrm{NO}$ emissions, it is seen that the percentage RGF in the mixture has a significant impact on the engine-out CO. As an example, the numerical results show that, for stoichiometric mixtures, if the measured/estimated RGF $=5 \%$ with a $\pm 2 \%$ error in the measurement/estimate, the error in the predicted $\mathrm{CO}$ is between 26 and 33\%. Figures 9 and 10 highlight the impact that the RGF can have on the engine-out emissions. The above results suggest that design and control engineers would have to account for the uncertainty in the accuracy of measuring/predicting RGF on data analyses and optimization/control strategies.

Figure 11 shows the temporal variation of the in-cylinder $\mathrm{NO}$ in the burned zone for lean mixtures (a) and rich mixtures (b). As expected, after the start of ignition (26 bTDC), there is very little NO. During the compression stroke the temperature of the burned zone increases while the cylinder volume decreases; hence the NO concentration increases and reaches its peak near the top dead center. After the combustion is complete, when all the fuel is burned (as in the lean case) or all the oxygen is used up (as in the rich case), the temperature of the burned gas starts decreasing as 


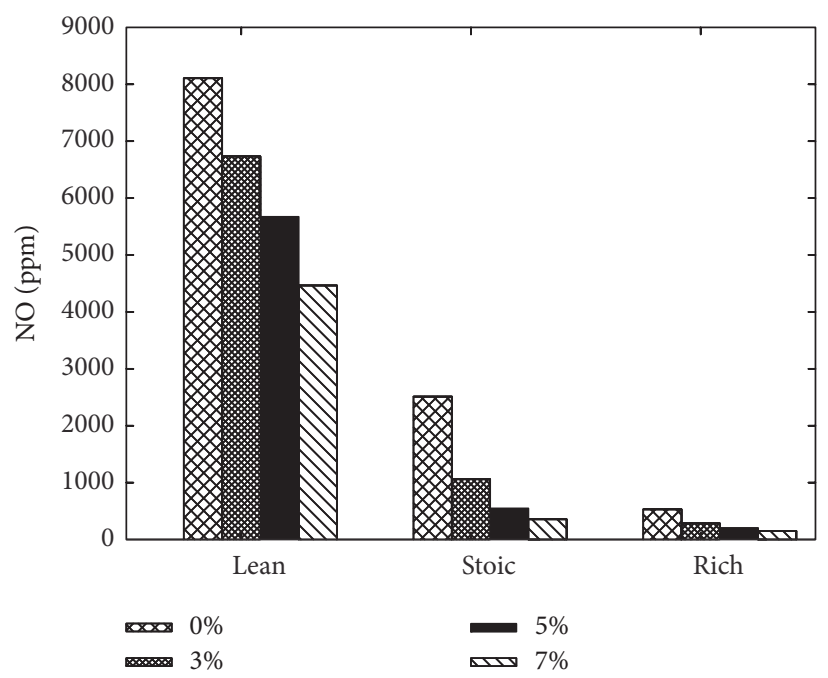

FIGURE 9: Effects of RGF and equivalence ratio on engine-out NO (ppm).

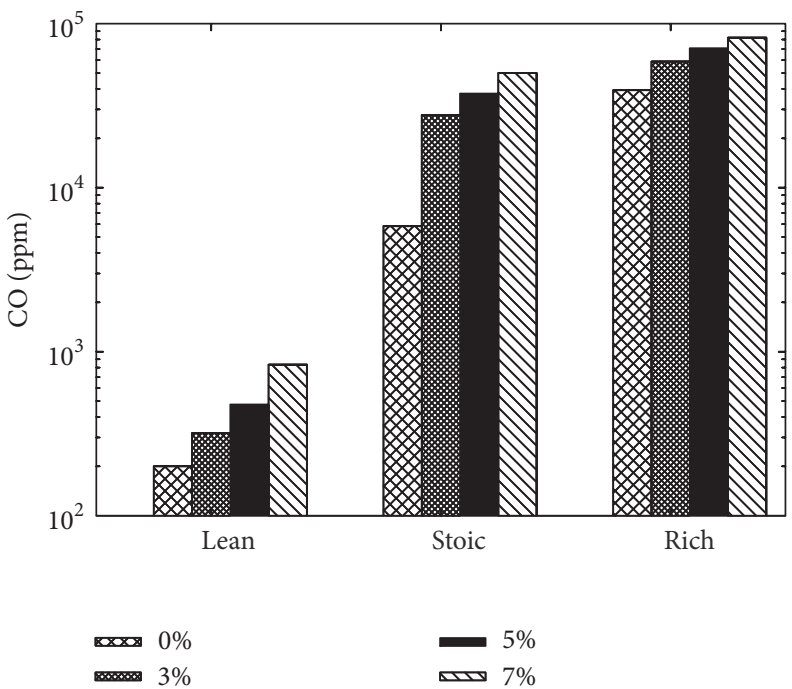

Figure 10: Effect of RGF and equivalence ratio on engine-out CO (ppm).

the cylinder volume increases (during the power or expansion stroke). During this period, the NO mass freezes and remains nearly constant until the exhaust value opens (at $140^{\circ}$ CAD). This well-known behavior of temporal NO variation is seen for both lean and rich mixtures with and without the RGF. The inclusion of the volume correction term in the rate equation for $\mathrm{NO}$ (and $\mathrm{CO}$ ) as discussed in (18) enables the prediction of the correct physical behavior of NO (and CO) moles during the expansion stroke.

Figure 12 shows the effect of RGF on the ratio of specific heats $(\gamma)$ for both the lean and rich mixtures. Increasing RGF increases the concentration of $\mathrm{CO}_{2}$ and $\mathrm{H}_{2} \mathrm{O}$ in the working fluid. As explained earlier, the higher specific heat values of $\mathrm{CO}_{2}$ and $\mathrm{H}_{2} \mathrm{O}$ tend to decrease the mixture-averaged value of $\gamma$. This behavior is seen for both lean and rich mixtures. This effect of reduction in $\gamma$ is similar to the effect of introducing EGR into the working fluid as discussed in [8].
As noted earlier, the low computational time for a complete cycle simulation of quasi-dimensional codes enables their use for design/parametric studies. Fast robust solvers were developed to enable the quasi-dimensional code used in this work to complete an engine cycle simulation in 70 milliseconds on a $2.93 \mathrm{GHz}$, Intel E7500 processor. Since the code runs at near real-time speeds, large-scale parametric engine cycle studies can be conducted with minimal computational resources and wall-time.

\section{Summary and Conclusions}

A well-validated, two-zone, quasi-dimensional engine model was used to conduct a numerical study of the sensitivity of the engine-out $\mathrm{NO}$ and $\mathrm{CO}$ emissions to the uncertainty in the percentage of residual gas fraction. Rate-control models for the formation of $\mathrm{NO}$ and $\mathrm{CO}$ included the effect of changing 


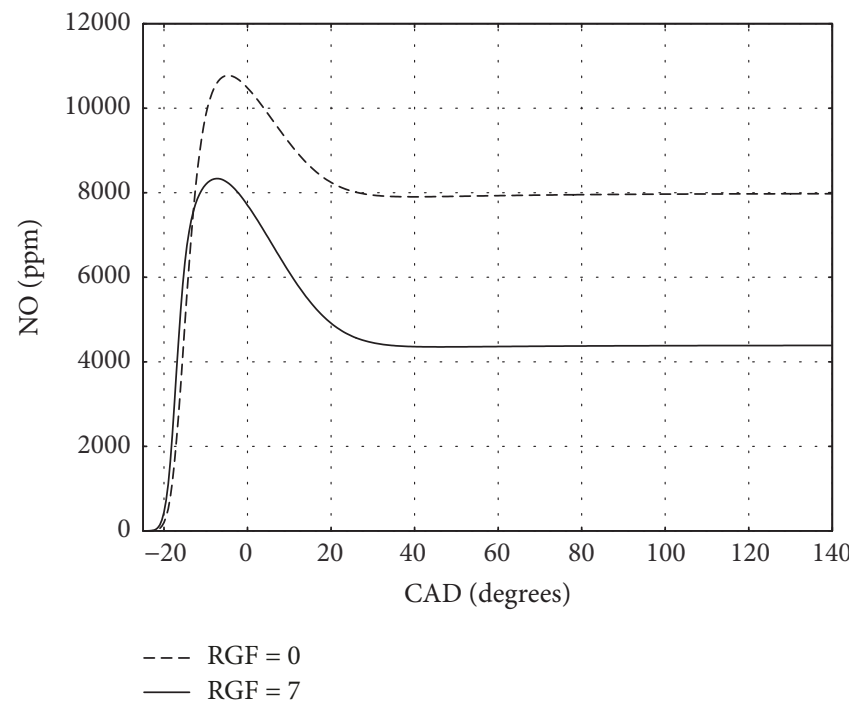

(a)

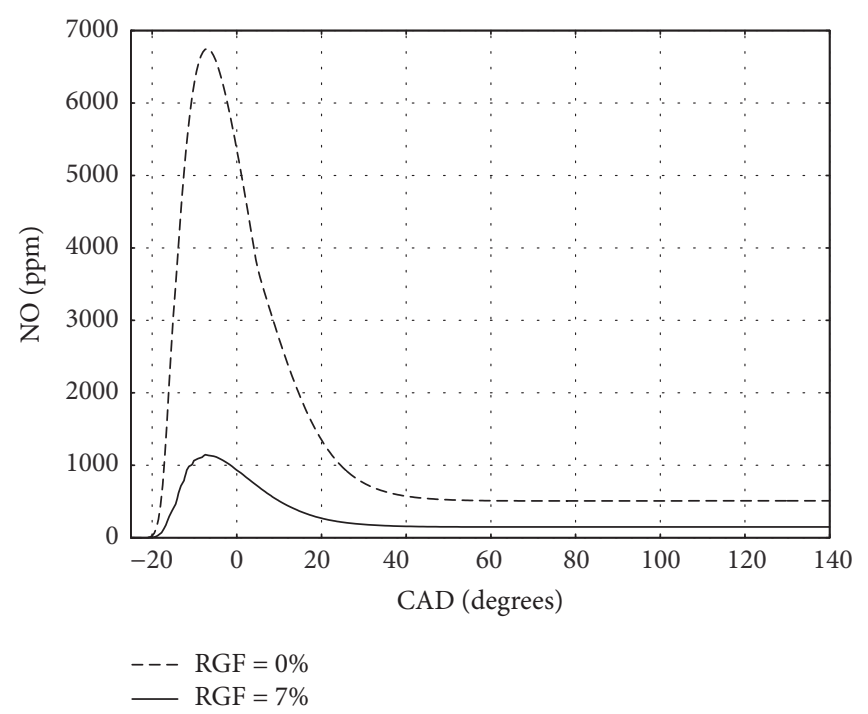

(b)

FIgURE 11: Temporal variation of in-cylinder NO: (a) lean mixture and (b) rich mixture.

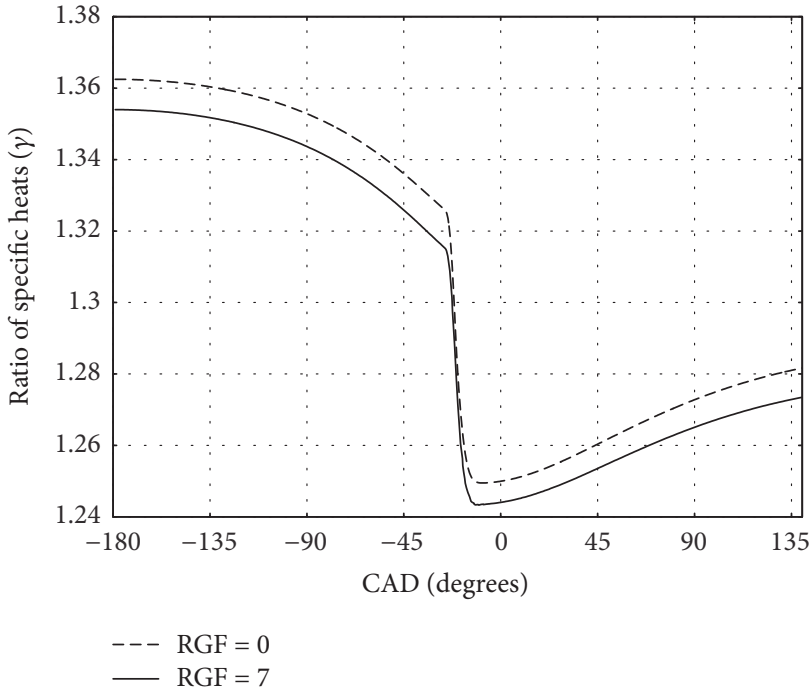

(a)

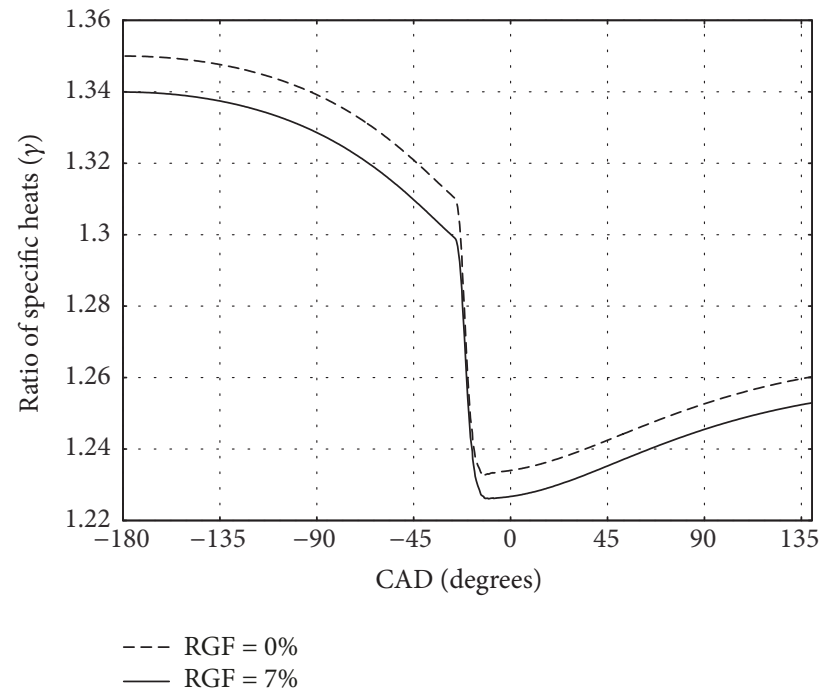

(b)

Figure 12: Temporal variation of ratio of specific heats: (a) lean mixture and (b) rich mixture.

cylinder volume. The mixture-averaged ratio of specific heat $(\gamma)$ computed based on the temperature and composition of the working fluid was used for more accurate prediction of the engine pressure and hence emissions. Detailed validation of the two-zone model for $\mathrm{NO}$ and $\mathrm{CO}$ was presented for a range of equivalence ratios. Temporal variations of $\mathrm{NO}$, $\mathrm{CO}$, and $\gamma$ were discussed. The model correctly predicts the combustion characteristics of lean, stoichiometric, and rich mixtures. Lean and stoichiometric mixtures undergo near complete combustion which leads to the formation of $\mathrm{CO}_{2}$ and $\mathrm{H}_{2} \mathrm{O}$ very close to the theoretically expected values, whereas rich mixtures yield a considerably higher concentration of $\mathrm{CO}$ as compared to lean and stoichiometric mixtures. The model also correctly predicts that the peak burned gas temperature occurs for the stoichiometric mixture for all RGF considered. The model also predicted the known trends of $\mathrm{NO}$ and $\mathrm{CO}$ emissions well. Inclusion of the volume correction term in the rate equations for $\mathrm{CO}$ and $\mathrm{NO}$ is necessary to capture the correct temporal variation of these species. Inclusion of the effects of mixture composition and temperature shows that the values of the mixture-averaged $\gamma$ decreases with an increase in RGF (as expected). The results of the numerical study showed that small uncertainties in the measured/computed values of RGF can have a significant impact on the engine-out $\mathrm{NO} / \mathrm{CO}$ emissions. Numerical results showed that a $2 \%$ error in the measured/estimated value of RGF can lead to a $20 \%$ error in the NO predictions for lean mixtures and about $30 \%$ percent 
error in $\mathrm{CO}$ predictions for stoichiometric mixtures. This study underscores the importance of taking into account the uncertainty in the measured/estimated value of RGF in the design and optimization of control algorithms for automotive emissions.

\section{Conflicts of Interest}

The author declares that there are no conflicts of interest regarding the publication of this paper.

\section{Acknowledgments}

This material was based upon work supported by the US Department of Energy, Office of Science, under Contract no. DE-AC02-06CH11357.

\section{References}

[1] W. W. Pulkrabek, Engineering fundamentals of the internal combustion engine, vol. 478, Prentice Hall, Upper Saddle River, NJ, USA, 1997.

[2] H. Ivansson, Estimation of the Residual Gas Fraction in an HCCI-Engine Using Cylinder Pressure [M.S. thesis], Vehicular Systems, Dept. of Electrical Engineering, Linköping University, Linköping, Sweden, 2003.

[3] S. Visakhamoorthy, T. Tzanetakis, D. Haggith, A. Sobiesiak, and J. Z. Wen, "Numerical study of a homogeneous charge compression ignition (HCCI) engine fueled with biogas," Applied Energy, vol. 92, pp. 437-446, 2012.

[4] V. Knop, J.-B. Michel, and O. Colin, "On the use of a tabulation approach to model auto-ignition during flame propagation in SI engines," Applied Energy, vol. 88, no. 12, pp. 4968-4979, 2011.

[5] E. A. Ortiz-Soto, G. A. Lavoie, J. B. Martz, M. S. Wooldridge, and D. N. Assanis, "Enhanced heat release analysis for advanced multi-mode combustion engine experiments," Applied Energy, vol. 136, pp. 465-479, 2014.

[6] U. Asad, C. Kelly, M. Wang, and J. Tjong, "Effects of intake air humidity on the $\mathrm{No}_{X}$ emissions and performance of a lightduty diesel engine," in Proceedings of the ASME 2012 Internal Combustion Engine Division Fall Technical Conference, (ICEF '12), pp. 235-242, American Society of Mechanical Engineers, New York, NY, USA, September 2012.

[7] J. B. Heywood, Choice Reviews Online, vol. 930, McGraw-Hill, New York, NY, USA, 1988.

[8] S. M. Aithal, "Impact of EGR fraction on diesel engine performance considering heat loss and temperature-dependent properties of the working fluid," International Journal of Energy Research, vol. 33, no. 4, pp. 415-430, 2009.

[9] P. K. Senecal, J. Xin, and R. D. Reitz, "Predictions of residual gas fraction in IC engines," SAE Technical Papers, 1996.

[10] H. Cho, K. Lee, J. Lee, J. Yoo et al., "Measurements and modeling of residual gas fraction in SI engines," SAE Technical Papers, 2001.

[11] J. W. Fox, W. K. Cheng, and J. B. Heywood, "A model for predicting residual gas fraction in spark-ignition engines," $S A E$ Technical Papers, 1993.

[12] A. A. Amer and L. Zhong, "A semi-empirical model for fast residual gas fraction estimation in gasoline engines," $S A E$ Technical Papers, 2006.
[13] S. Verhelst and C. G. W. Sheppard, "Multi-zone thermodynamic modelling of spark-ignition engine combustion - An overview," Energy Conversion and Management, vol. 50, no. 5, pp. 13261335, 2009.

[14] P. Giansetti and P. Higelin, "Residual gas fraction measurement and estimation in spark ignition engine," SAE Technical Papers, no. 2007-01-1900, 2007.

[15] H. Cho, K. Lee, J. Lee, J. Yoo, and K. Min, "Measurements and modeling of residual gas fraction in SI engines," SAE Technical Papers, 2001.

[16] G. Fontana and E. Galloni, "Variable valve timing for fuel economy improvement in a small spark-ignition engine," Applied Energy, vol. 86, no. 1, pp. 96-105, 2009.

[17] H. Xie, L. Li, T. Chen, and H. Zhao, "Investigation on gasoline homogeneous charge compression ignition (HCCI) combustion implemented by residual gas trapping combined with intake preheating through waste heat recovery," Energy Conversion and Management, vol. 86, pp. 8-19, 2014.

[18] T. Alger and S. Wooldridge, "Measurement and analysis of the residual gas fraction in an SI engine with variable cam timing," SAE Technical Papers, 2004.

[19] L. M. Olesky, J. B. Martz, G. A. Lavoie, J. Vavra, D. N. Assanis, and A. Babajimopoulos, "The effects of spark timing, unburned gas temperature, and negative valve overlap on the rates of stoichiometric spark assisted compression ignition combustion," Applied Energy, vol. 105, pp. 407-417, 2013.

[20] S. M. Aithal and S. M. Wild, "ACCOLADES: A scalable workflow framework for large-scale simulation and analyses of automotive engines," Lecture Notes in Computer Science (including subseries Lecture Notes in Artificial Intelligence and Lecture Notes in Bioinformatics): Preface, vol. 9137, article no. A7, pp. 87-95, 2015.

[21] G. Woschni, "A universally applicable equation for the instantaneous heat transfer coefficient in the internal combustion engine," SAE Technical Paper no. 670931, 1967.

[22] R. Kee, F. M. Rupley, and J. A. Miller, “Chemkin-III: A Fortran chemical kinetics package for the analysis of gas-phase chemical and plasma kinetics," Technical Report, USDOE Office of Energy Research, Washington, DC, USA, 1996.

[23] I. Andersson and L. Eriksson, "A parametric model for ionization current in a four stroke SI engine," Journal of Dynamic Systems, Measurement, and Control, vol. 131, no. 2, pp. 1-11, 2009.

[24] F. Perini, F. Paltrinieri, and E. Mattarelli, "A quasi-dimensional combustion model for performance and emissions of SI engines running on hydrogen-methane blends," International Journal of Hydrogen Energy, vol. 35, no. 10, pp. 4687-4701, 2010.

[25] S. M. Aithal, "Prediction of voltage signature in a homogeneous charge compression ignition (HCCI) engine fueled with propane and acetylene," Combustion Science and Technology, vol. 185, no. 8, pp. 1184-1201, 2013.

[26] M. Biruduganti, S. Gupta, B. Bihari, S. McConnell, and R. Sekar, "Air separation membranes - An alternative to EGR in large bore natural gas engines," in Proceedings of the 2009 ASME Internal Combustion Engine Division Spring Technical Conference, pp. 21-30, USA, May 2009.

[27] A. Aziz Hairuddin, A. P. Wandel, and T. Yusaf, "Effect of different heat transfer models on a diesel homogeneous charge compression ignition engine," International Journal of Automotive and Mechanical Engineering, vol. 8, no. 1, pp. 1292-1304, 2013.

[28] H. S. Soyhan, H. Yasar, H. Walmsley, B. Head, G. T. Kalghatgi, and C. Sorusbay, "Evaluation of heat transfer correlations for 
HCCI engine modeling," Applied Thermal Engineering, vol. 29, no. 2-3, pp. 541-549, 2009.

[29] C. K. Law, A. Makino, and T. F. Lu, "On the off-stoichiometric peaking of adiabatic flame temperature," Combustion and Flame, vol. 145, no. 4, pp. 808-819, 2006. 


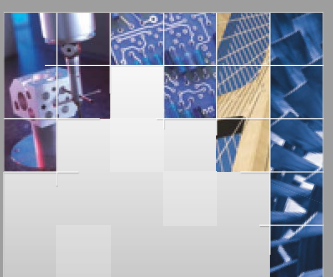

\section{Enfincering}
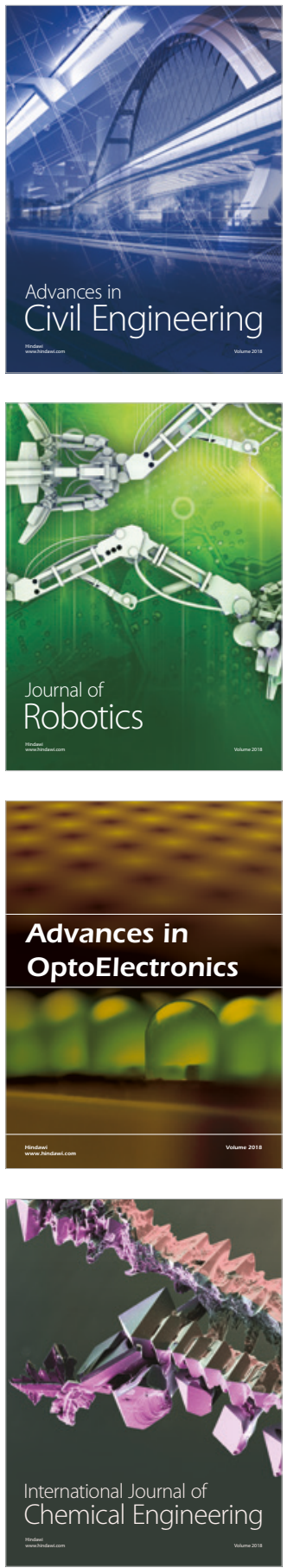

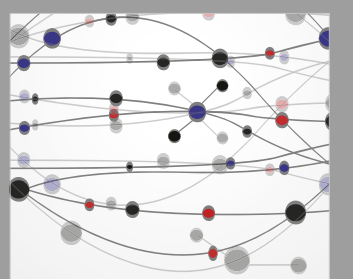

\section{Rotating \\ Machinery}

The Scientific World Journal

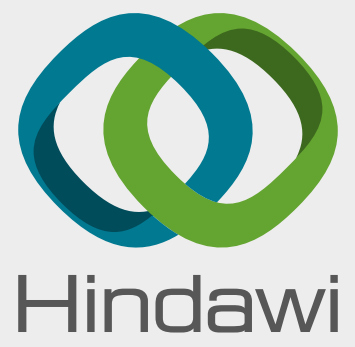

Submit your manuscripts at

www.hindawi.com
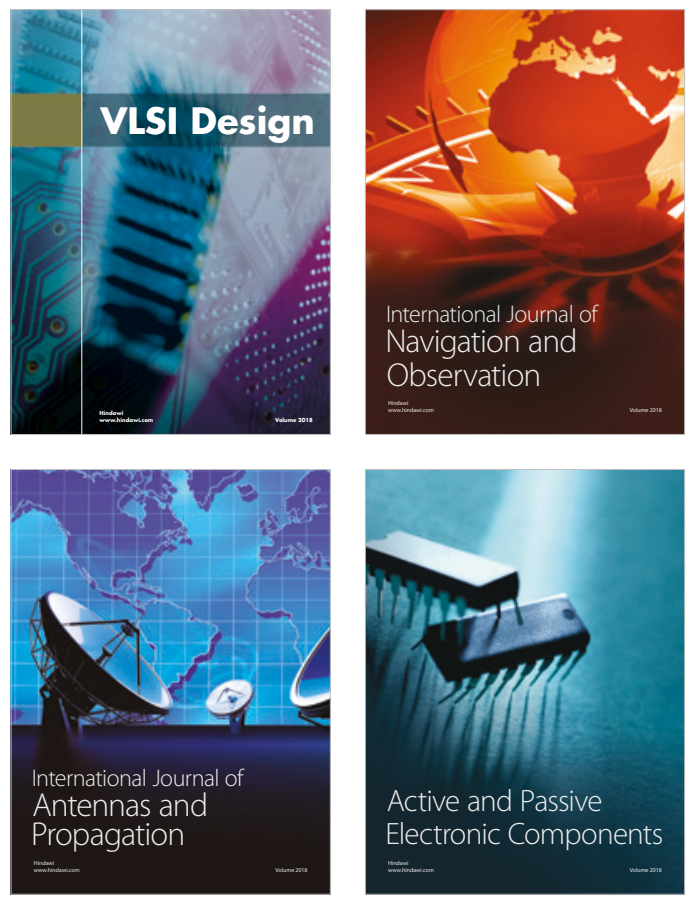
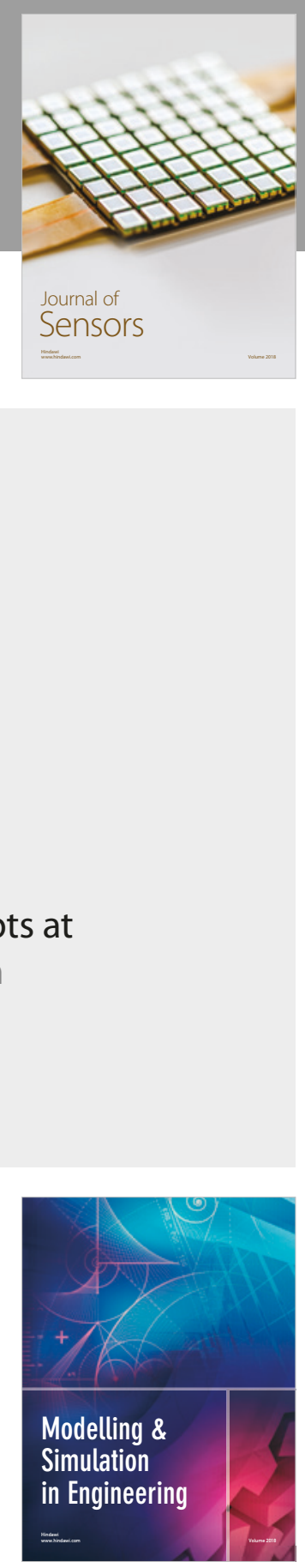

\section{Advances \\ Multimedia}
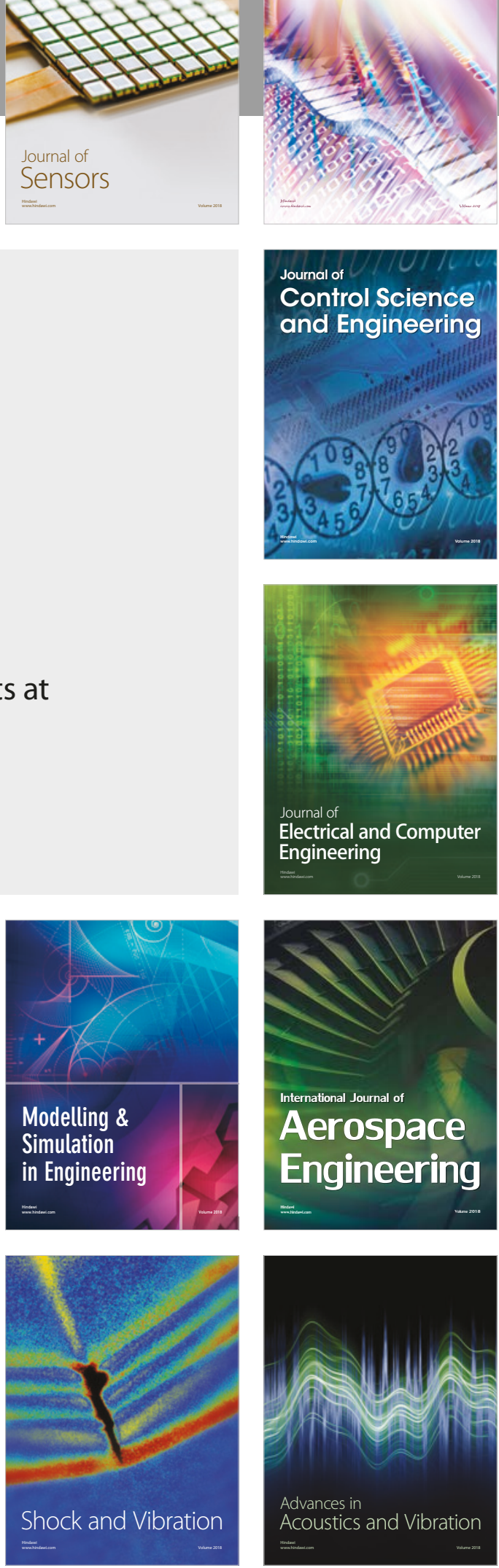